\title{
MAPEAMENTO ESTRATÉGICO E TECNOLÓGICO: PRODUÇÃO DE ÁCIDO SUCCÍNICO A PARTIR DO BAGAÇO DE CANA
}

\author{
SUZANA BORSCHIVER ${ }^{1}$, M. A. P. G. COUTO ${ }^{2}$ e K.M.COELHO ${ }^{3}$
}

\author{
${ }^{1}$ UFRJ- EQ \\ ${ }^{2}$ Universidade Federal do Rio de Janeiro, Escola de Química, Núcleo de Estudos Industriais e \\ Tecnológicos (NEITEC) \\ ${ }^{3}$ Universidade Federal do Rio de Janeiro, Departamento de Engenharia Bioquímica
}

\begin{abstract}
RESUMO - Ações vêm sendo tomadas, em nível mundial, para mover a economia de uma base fóssil para uma mais sustentável, centrada na biomassa. No caso do ácido succínico, parte de sua produção deriva do petróleo, mas sua bioprodução a partir de recursos renováveis pode ser atrativa devido ao potencial de obtenção de vários insumos e produtos para a indústria química. $\mathrm{O}$ trabalho recorreu a análise de artigos (SCIRUS), patentes solicitadas e concedidas (USPTO) para identificar tendências tecnológicas e mercadológicas do ácido succínico a partir de bagaço de cana, de 2008 a 2013.China, EUA, Holanda e Índia se destacaram em artigos (43\% e 10\%). Os focos principais foram microorganismos (Actinobacillus succinogenes) e pré-tratamento. Já os focos das patentes foram tecnologia microbiana, de fermentação, pre-tratamento e microorganismo. Tanto em patentes concedidas quanto solicitadas, os EUA destacaram - se (mais de 50\%) assim como as empresas Novozyme, Ajinomoto e a BioAmber.
\end{abstract}

\section{INTRODUÇÃO}

A expectativa com a diminuição das reservas de petróleo e a elevação dos custos para sua obtenção, aliadas à crescente preocupação com a preservação ambiental, vêm exigindo soluções tecnológicas imediatas às necessidades de consumo.

Pesquisas acadêmicas demonstram um enorme potencial das biomassas de composição lignocelulósica, que são as fontes de carboidratos mais abundantes na natureza, para aplicação em diversos campos, e a esta amplitude de possibilidades convencionou-se chamar de "biorrefinaria". O termo biorrefinarias compreende as instalações e os processos nos quais matérias-primas renováveis e seus resíduos são transformados em biocombustíveis, produtos e insumos químicos, energia e alimentos. Neste sentido, as biomassas assumem posição estratégica na era pós-petróleo, uma vez que representam a grande fonte de materiais renováveis a serem utilizadas. Estas tendências fundamentais provocaram um grande interesse em produtos de base biológica e os colocou no topo da agenda estratégica da maioria dos players em uma variedade de indústrias. 
No Brasil, o bagaço de cana é uma das principais biomassas lignocelulósicas (60-70\% de carboidratos), sendo produzido cerca de $250 \mathrm{~kg}$ por tonelada de cana. A maior parte é queimada em usinas de açúcar e destilarias de álcool para a geração de energia, e uma fração menor é usada para a alimentação animal; no entanto, há ainda algum excedente. Betancur e Pereira Jr (2010) estimam que, com o aumento da produção de cana, em resposta ao crescimento da demanda global de etanol mais bagaço excedente estará disponível apontando para um grande potencial de produção de combustíveis e produtos químicos, entre estes o ácido succínico.

Atualmente, a maioria do ácido succínico produzido comercialmente resulta da síntese química envolvendo a hidrólise de produtos derivados do petróleo. Esse processo se dá com a oxidação do butano até anidrido maleico, que é hidrolisado até obtenção do ácido maleico (CORNIL e LAPPE, 2002 apud Borges, 2011). Em seguida, mediante sua hidrogenação é obtido o ácido succínico (ZEIKUS et al., 1999 apud Borges, 2011).

Segundo Song e Lee (2006), a bioprodução de ácido succínico a partir de recursos renováveis pode ser mais rentável do que os processos à base de petróleo. $\mathrm{O}$ ácido biosuccínico é produzido a partir da fermentação de uma fonte de carbono tal como um carboidrato, por exemplo, glicose, seguida de etapas de recuperação e purificação.

Esse ácido constitui-se na base para o fornecimento de uma série de substâncias intermediárias e produtos finais importantes na indústria química, principalmente de biopolímeros a partir de succinato, além de ser um componente chave na produção de mais de 30 produtos comercialmete importantes, na indústria de alimentos, farmacêutica e de cosméticos (MCKINLAY et al., 2007 apud Borges, 2011; ZEIKUS et al., 1999 apud Borges, 2011; SONG e LEE, 2006).

No cenário da produção industrial, a inovação é uma questão de sobrevivência para as empresas e, portanto, deve ser considerada na tomada de decisões. Para mensurar o patamar de inovação global e as diretrizes tecnológicas mundiais, são realizados estudos prospectivos. (BORSCHIVER, 2008)

Os Estudos de Prospecção Tecnológica, também chamados de estudos de futuro, ou forecast(ing), foresight(ing) ou future studies, fornecem as principais tendências no contexto mundial sendo possível segmentar estas tecnologias por setor da economia. Estes estudos auxiliam a identificação de tecnologias promissoras, úteis para uma determinada organização, bem como apontam para possibilidades de negócios e parcerias. A sistematização da prática de monitoramento tecnológico, a ser coberta pela prospecção tecnológica e de inovação, visa congregar a busca de soluções adequadas para a identificação e priorização de uma agenda de $\mathrm{P} \& \mathrm{D}$, articulada com instituições de pesquisa, que possa inclusive influenciar agenda de $\mathrm{P} \& \mathrm{D}$ nacional e criar demandas para a cadeia inovativa do setor. (BORSCHIVER, 2008)

Com base no exposto e, diante da importância do ácido succínico como insumo para o setor químico, o presente trabalho tem como objetivo identificar as tendências tecnológicas e de mercado para os próximos anos da produção de ácido succínico a partir do bagaço de cana mediante um estudo de prospecção tecnológica. 


\section{METODOLOGIA}

Este trabalho se desenvolveu em duas etapas. A primeira etapa "Fase Pré-prospectiva" é uma fase de pesquisa preliminar, se constituindo em uma busca menos direcionada, procurando informações acerca do objeto de estudo e que vislumbra a constituição de uma base de informações que suportará a próxima fase. A segunda etapa, "Fase de Prospecção Tecnológica", é baseada em uma metodologia definida com palavras-chave específicas (busca mais direcionada), buscas em documentos técnicos (artigos científicos e patentes) e acompanhada por uma análise mais detalhada, em que os documentos encontrados são analisados por vários critérios, tais como ano de publicação, país de origem, tipo de autor e foco sobre o objeto de estudo.

A Fase Pré-prospectiva constitui uma etapa fundamental da metodologia, pois se baseia em uma pesquisa preliminar em que os assuntos/campos relacionados ao tema/objeto de estudo são levantados em mídias especializadas. E a partir desses conhecimentos tem-se o embasamento para definição de palavras-chave para Fase de Prospecção em si onde são mostrados os players no momento atual, com tecnologias que são parte do escopo do estudo.

Para a pesquisa foram utilizadas as palavras chaves e suas combinações "sugarcane bagasse", "succinic acid", "bio-based succinic acid", "succinic acid production", "bagasse" e "actinobacillus" em buscas por artigos científicos na ferramenta de busca SCIRUS. A pesquisa foi desenvolvida com as palavras-chave e suas combinações "succinic acid", "sugarcane bagasse, "succinic acid recovery", "membrane", "succinic acid production", "actinobacillus", "BioAmber", "Myriant", "Basf", "Mitsubishi" em buscas por patentes na base de dados norte-americana USPTO (United States Patent and Trademark Office). Neste contexto foram analisados diversos documentos técnicos em um horizonte de tempo definido, de 2008 a 2013.

\section{RESULTADOS E DISCUSSÕES}

\subsection{Análise dos Artigos}

Análise Macro: A análise Macro cobre a série histórica de publicações, os países que apresentam maior número de artigos no período estudado e os mais importantes jornais, universidades, centros de pesquisa e empresas ligadas ao conhecimento científico e desenvolvimento de processos de produção do ácido succínico a partir do bagaço de cana.

A primeira análise é a evolução da produção científica em número de artigos por ano. De acordo com a Figura 1, verificou-se que, nos últimos quatro anos (2009-2013) houve um crescimento significativo no interesse em torno do ácido biosuccínico, se considerado o aumento no número de publicações por ano. Em 2012, atingiu-se o pico em número de artigos com 8 publicações, de um total de 28 artigos. No ano de 2013 foram observadas 7 publicações, todavia, este número inferior é justificado pois o ano está incompleto, considerando apenas as publicações até o mês de julho. 


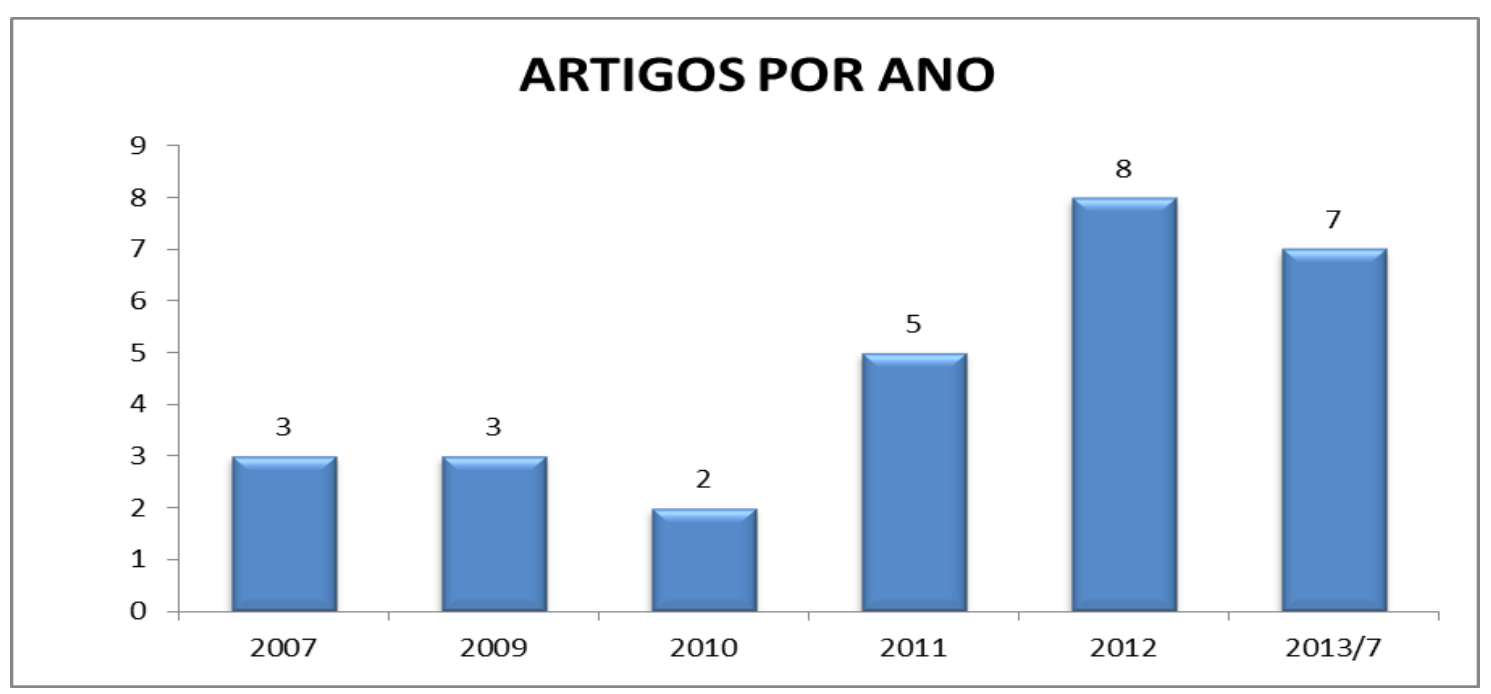

Figura 1 - Análise temporal: Distribuição dos Artigos por ano.

Outra análise refere-se à origem das publicações, identificando-se os países que mais estão direcionando esforços científicos para a produção do ácido succínico a partir do bagaço de cana. A China lidera na publicação de artigos a partir da base de estudo, com $43 \%$ dos artigos analisados. Em sequência, entre os países que mais publicaram artigos sobre o tema, aparece os Estados Unidos, a Holanda e a Índia com $10 \%$.

Analisando os dados, a revista científica que destaca-se por ter publicado a maioria dos artigos foi a Bioresearch Technology, com 12 artigos. Considerando o tipo de autor (universidade, instituto de pesquisa, empresas), quase todas as publicações foram realizadas por pesquisadores de universidades. Este resultado é esperado pela natureza dos artigos científicos. Aprofundando nesse contexto as universidades chinesas foram as que apareceram com mais artigos, por exemplo, Nanjing University Technology apareceu com 4 artigos e Beijing Forestry University, South China University of Technology, Chinese Academy of Sciences com 3 artigos.

Análise Meso: Na Análise Meso, os artigos são categorizados de acordo com os aspectos mais relevantes em torno da produção de ácido succínico a partir do bagaço de cana. Estes aspectos foram devidamente identificados na etapa inicial do estudo com o foco de apontar as grandes áreas identificadas quanto ao tema. As grandes áreas de exploração propostas para todas as análises foram:

- Equipamento - quando foram identificados no documento equipamento(s) utilizados no processo;

- Microorganismo - quando foram identificadas no documento microorganismo(s) para a produção de ácido succínico;

- Tecnologia de pré-tratamento - quando foram identificadas no documento tecnologia(s) para quebrar a estrutura de biomassa e fazer os seus componentes mais acessíveis para o processo subsequente de hidrólise (química, física, físico-química);

- Tecnologias de tratamento (química, bioquímica, termoquímica) - quando foram identificadas no documento tecnologia(s) para quebrar a estrutura da biomassa que teve que passar por uma etapa anterior de pré-tratamento; 
- Biotecnologia Microbiana - quando foram identificadas no documento tecnologia(s) de isolamento de microrganismos e linhagens recombinantes

- Tecnologia de Fermentação - quando foram identificadas no documento estratégias de fermentação como: utilização de enzimas, simultaneamente com a ação de microorganismos, Simultaneous Saccharification and Fermentation (SSF), ou separadamente, Separated Hydrolysis and Fermentation (SHF). Ou até mesmo o uso de diferentes microrganismos em fases sucessivas, ou de microrganismos recombinantes para utilizar o máximo dos açúcares disponíveis (substratos), Simultaneous Saccharification and Co-Fermentation (SSCF) e Consolidated Bioprocess (CBP) respectivamente.

- Tecnologia de recuperação - quando foram identificadas no documento tecnologia(s) utilizadas para a recuperação de ácido succínico;

- Membrana - quando foram identificadas no documento a utilização de membrana(s) para recuperação do produto.

A Figura 2 apresenta a Análise Meso dos artigos. Pode -se observar que a maioria dos artigos apresenta informações de microorganismos (22\%), seguido por tecnologia de prétratamento $(17 \%)$. Os microrganismos que tiveram mais citações foram a bactéria Actinobacillus succinogenes (9 artigos), seguido pela bactérias Escherichia coli (7 artigos) e com o mesmo número de citações (3 artigos), a bactéria Corynebacterium glutamicum e levedura Saccharomyces cerevisiae. No que se refere ao tipo de pré-tratamento identificado pode-se destacar a hidrólise ácida.

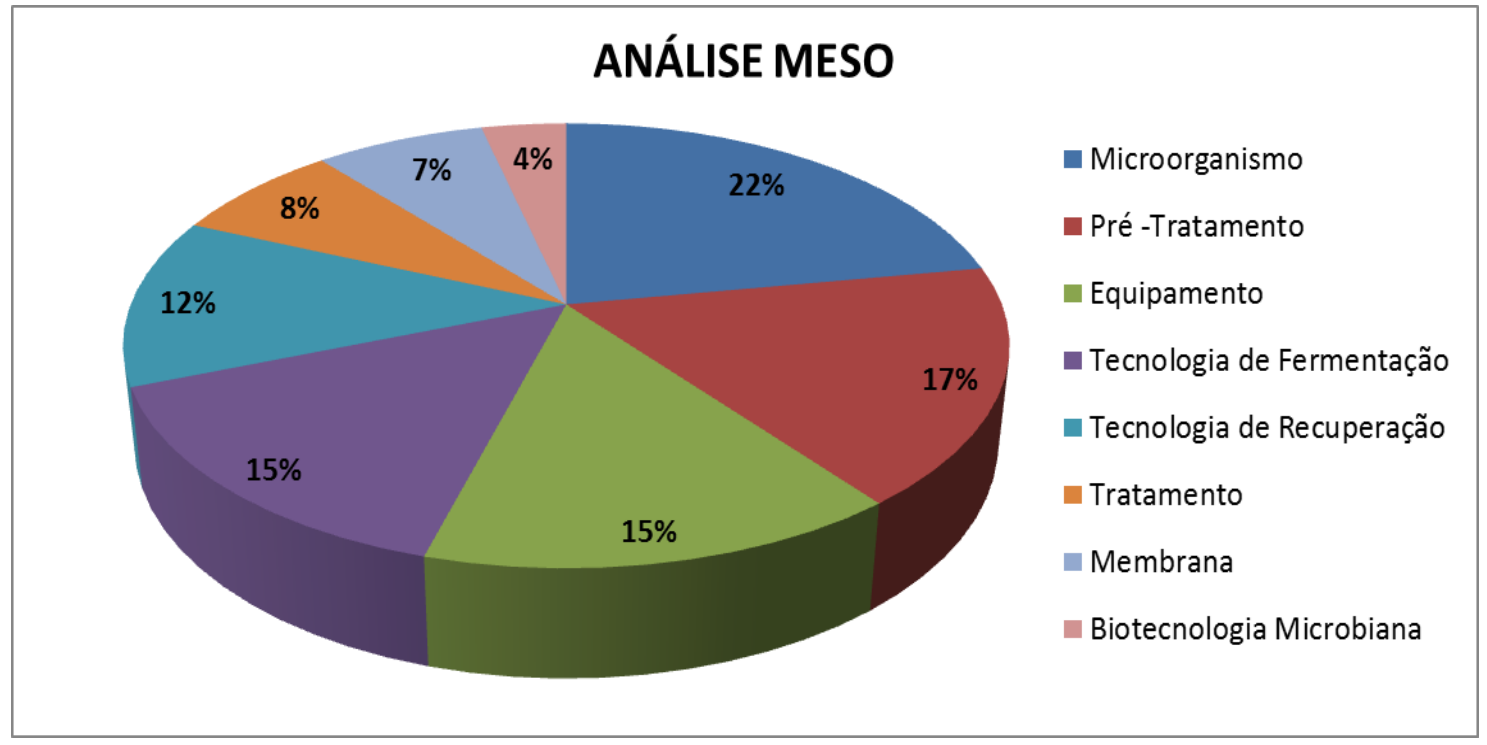

Figura 2 - Análise Meso: Distribuição dos Artigos pelas taxonomias meso.

\subsection{Análise das Patentes Concedidas}

Análise Macro: A evolução do conhecimento tecnológico em número de patentes concedidas por ano mostrou que houve um crescimento grande a partir de 2010. Este cenário 
também pode ser observado na análise dos artigos científicos, comprovando que nos últimos quatro anos surgiram maior interesse pelo ácido biosuccínico.

A análise dos países de origem dessas patentes concedidas mostrou que grande parte da inovação é atribuída aos Estados Unidos, com 62\%. Seguido pela Dinamarca, em conjunto com os EUA (21\%). As empresas destacaram-se como principal depositante das patentes concedidas, $85 \%$ dos documentos. Sendo a Novozymes a proprietária da maior parcela, $46 \%$, seguida por Ajinomoto, com 16\% e Danisco|DuPont com $8 \%$.

Análise Meso: A Figura 3 mostra a Análise Meso das patentes concedidas. Olhando para os resultados percebe um equilíbrio na distribuição pelas taxonomias, destacando-se a tecnologia microbiana, 19\% dos documentos. Aprofundando na análise da tecnologia microbiana, nas patentes concedidas destacaram-se a utilização de células mutantes no processo.

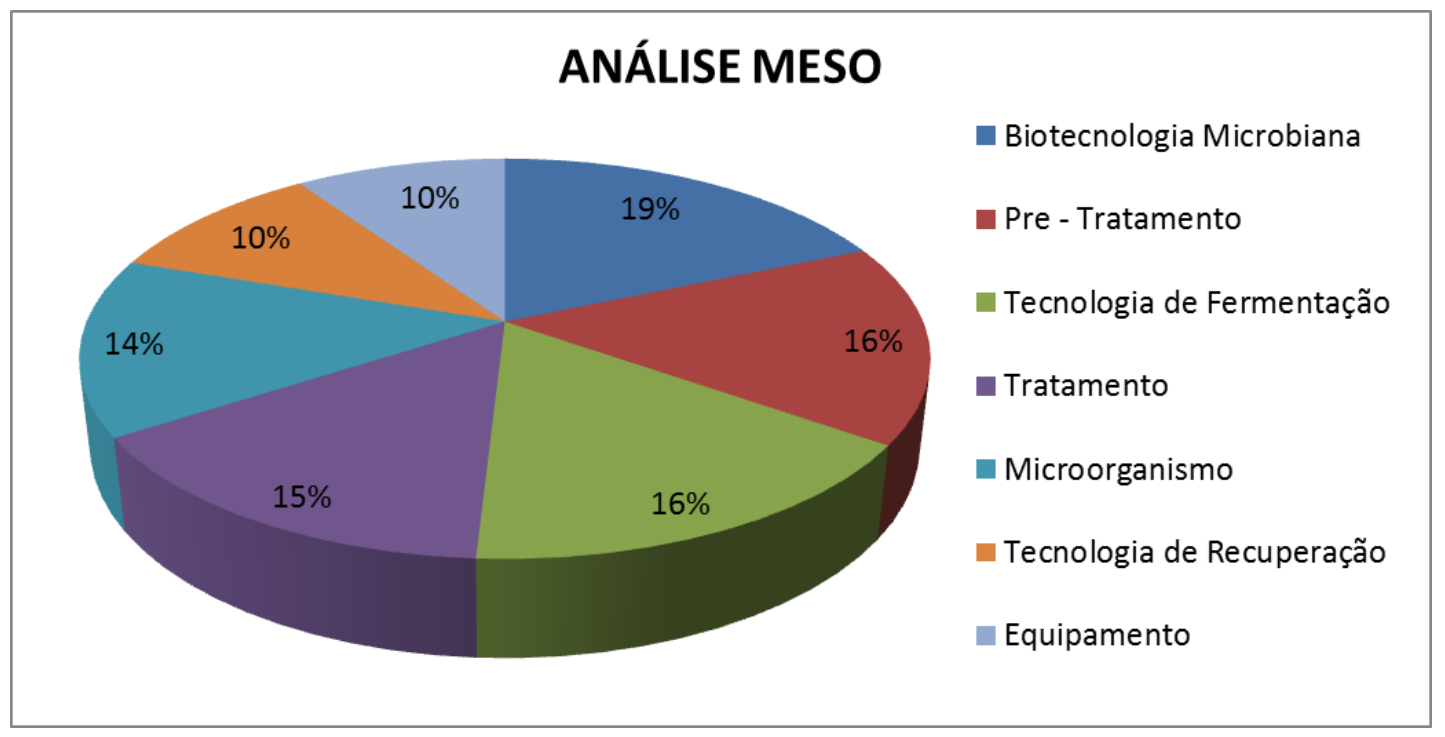

Figura 3 - Análise Meso: Distribuição das Patentes Concedidas pelas taxonomias Meso.

\subsection{Análise das Patentes Solicitadas}

Análise Macro: A análise temporal das patentes solicitadas assim como observado para artigos e patentes concedidas teve um crescimento em número de patentes concedidas em relação aos anos anteriores. Em 2012, teve-se o maior número de patentes solicitadas com 25 documentos, de um total de 56 patentes. No ano de 2013 até o mês de julho foram observadas 16 patentes. Outra análise refere-se à origem das patentes solicitadas, identificando-se os países que mais estão direcionando esforços científicos para a produção de ácido biossuccínico a partir do bagaço. Os Estados Unidos aparece como país com maior número de patentes solicitadas (31 patentes) e repete a liderança observada na análise das patentes concedidas. Em seguida, temos a Dinamarca com 7 patentes e o Japão com 6 patentes solicitadas. 
No perfil do solicitante de patentes, $77 \%$ das patentes tiveram origem nas empresas, $14 \%$ inventores e $9 \%$ centro de pesquisa. Entre as empresas solicitantes destacam-se a Novozymes ( 9 patentes), repetindo a liderança observada na análise das patentes concedidas, seguida pela BioAmber ( 8 patentes) e Renmatix ( 7 patentes) como pode-se ver na Figura 4.

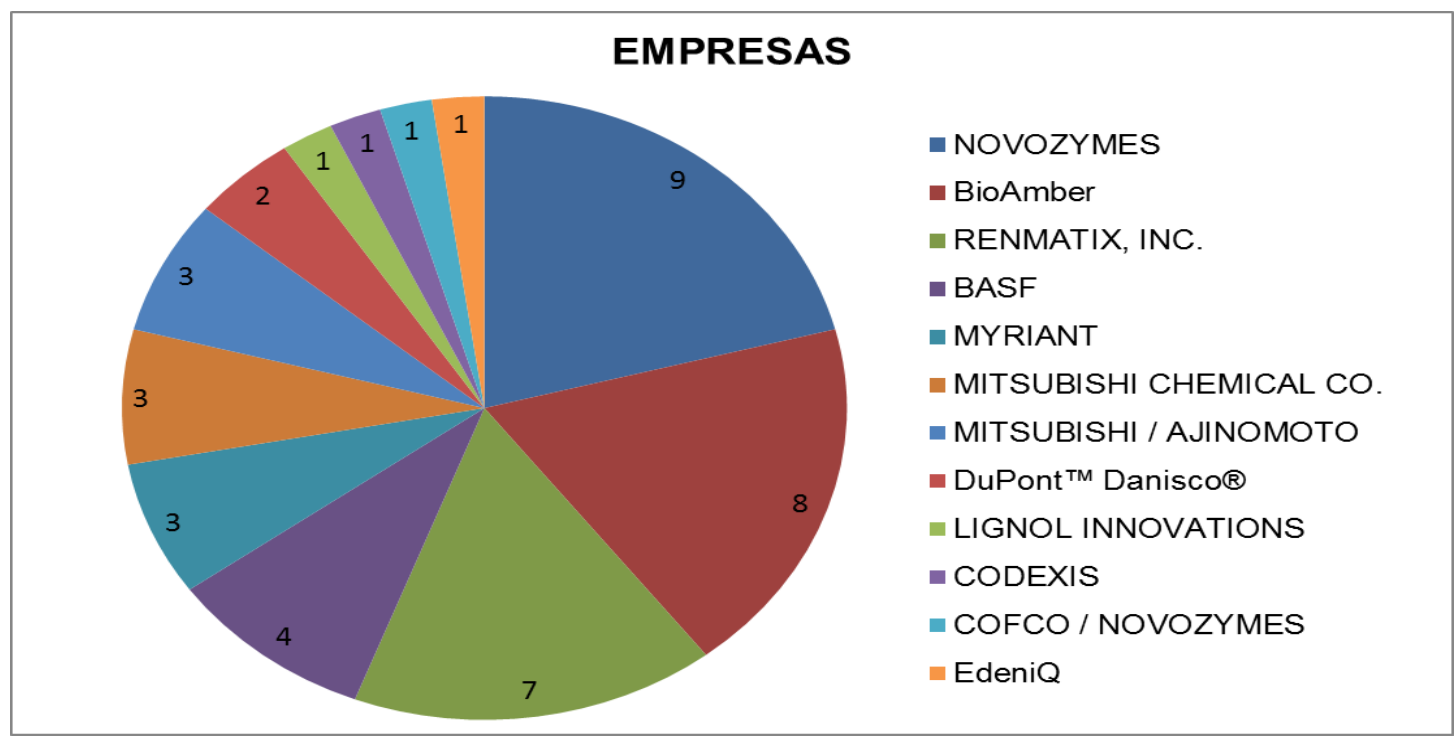

Figura 4 - Distribuição das Empresas solicitantes

Análise Meso: Assim como na análise de patentes concedidas teve-se uma distribuição equilibrada das taxonomias Meso, destacando-se microorganismo, com 16\%, tecnologia microbiana, $15 \%$ dos documentos. Aprofundando na análise, o microorganismo citado em mais patentes foi a Escherichia coli com 11 referências em patentes solicitadas, seguido por Saccharomyces cerevisiae, Mannheima succinoproducens e Candida todos com 5 citações.

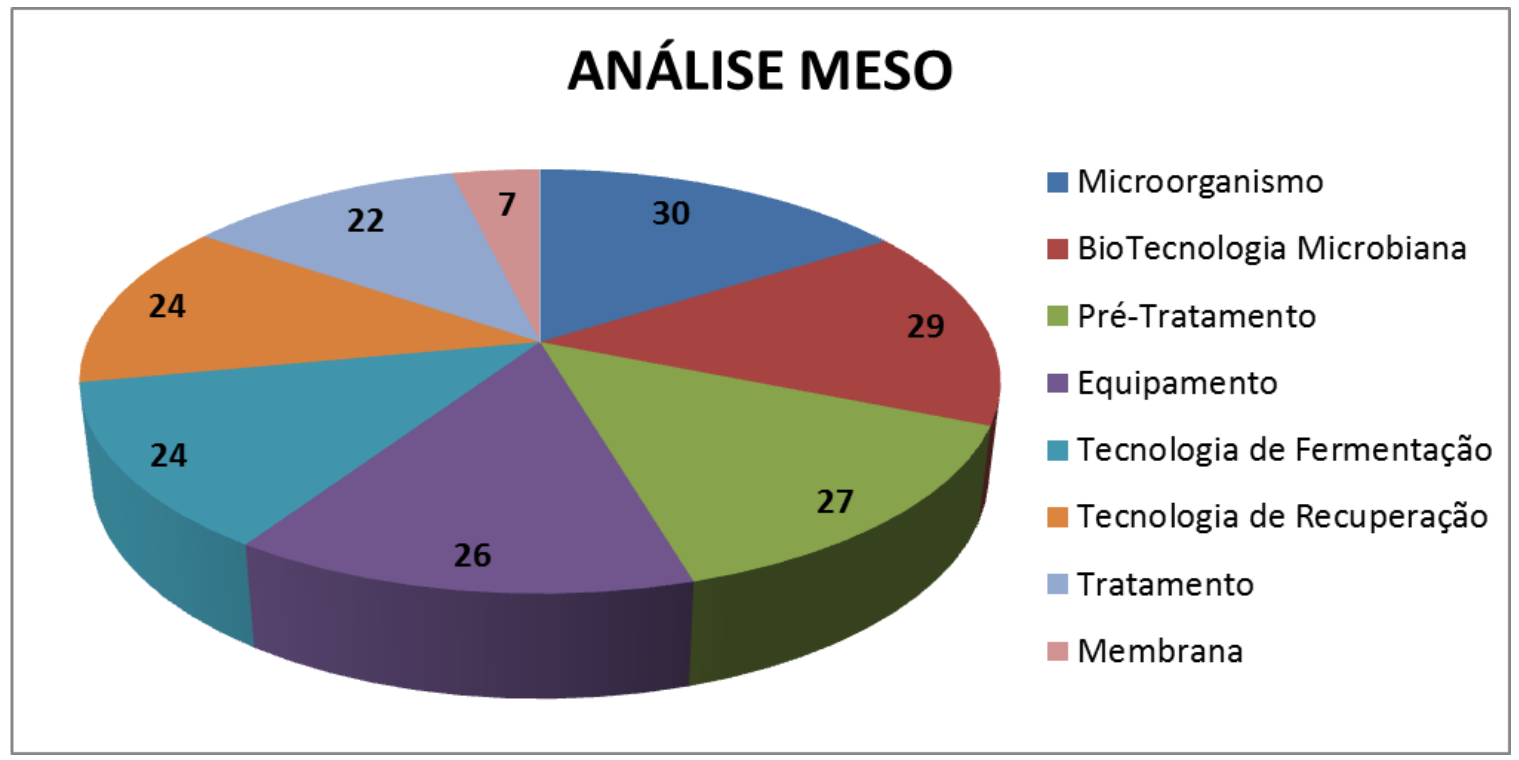

Figura 5 - Análise Meso: Distribuição das Patentes Solicitadas pelas taxonomias Meso. 


\section{CONSIDERAÇÕES FINAIS}

Após a análise do trabalho, pode-se observar algumas tendências no que diz respeito ao estudo de prospecção tecnológica do ácido biosuccínico a partir do bagaço de cana.

A China possui a maior produção acadêmica quanto ao tema apesar de não ser produtora de etanol de cana este país tem centrado esforços em pesquisas sobre biomassas derivadas de cana. Uma das causas pode ser o fato da mesma possuir investimentos em alguns lugares do mundo, nessa área, inclusive no Brasil. Pode-se destacar como proprietários de patentes, solicitadas e concedidas, os Estados Unidos seguido pela Dinamarca, grande parte proveniente da empresa Novozyme. Apesar de o Brasil ser um grande produtor de bagaço, percebe-se uma atuação tímida dele na publicação de artigos e no depósito de patentes. $\mathrm{O}$ estudo das tecnologias de pré-tratamento da biomassa foi o foco na maioria dos documentos analisados, seguido pela biotecnologia microbiana e microorganismos. O pré-tratamento químico mais especificamente a hidrólise ácida obteve mais citações na pesquisa. A utilização de linhagens recombinantes destacou-se como técnica de biotecnologia microbiana. A bactéria Actinobacillus succinogenes foi a mais mencionada nos artigos, o que demostra seu grande potencial para produção industrial de ácido biossuccínico, em patentes destacou-se a Escherichia coli. Por fim, a valorização de fontes renováveis como matérias-primas para diversas aplicações é um estímulo importante que poderá nortear a decisão sobre quais desenvolvimentos deverão ser priorizados.

\section{REFERÊNCIAS}

BORSCHIVER, S. Apostila de Curso de Pós Graduação, EQ/UFRJ, 2008.

CORNILS, B.; LAPPE, P. - Dicarboxylic acids, aliphatic. Ullmann's Enzyklopedia of industrial chemistry, Wiley-VCH, Weinheim, 2002.

MCKINLAY, J.B.; SHACHAR-HILL, Y.; ZEIKUS, J.G.; VIEILLE, C. - Determining Actinobacillus succinogenes metabolic pathways and fluxes by NMR and GC-MS analyses of C-13-labeled metabolic product isotopomers, Metab Eng, 9: 177-92, 2007.

Portal Única - Estrangeiros são a nova geração de usineiros, 2013, disponível em http://www.unica.com.br/unica-na-midia, acesso em 20/03/2014

SONG, H.; LEE, S.Y. - Production of succinic acid by bacterial fermentation. Enzyme and Microbial Technology, 39, 352-361, 2006.

ZEIKUS, J.G.; JAIN, M.K.; ELANKOVAN P. - Biotechnology of succinic acid production and markets for derived industrial products, Appl Microbiol Biotechnol, 51(5):545-552, 1999 